\title{
The Molecular Structure of 4-Methyl Benzenesulfonyl Chloride
}

\author{
G. Rigotti ${ }^{+}$, B. E. Rivero ${ }^{+}$, and R. R. Filgueira ${ }^{++*}$ \\ Departamento de Física, Universidad Nacional de La Plata, C.C. 67, 1900 La Plata, Argentina \\ + Member of the Carrera del Investigador Científico of the CIC, \\ Provincia de Buenos Aires, Argentina \\ ${ }^{++}$Member of the Carrera del Investigador Científico of the CONICET, Argentina \\ Z. Naturforsch. 41 b, 1107-1111 (1986); received April 14, 1986 \\ 4-Methyl Benzenesulfonyl Chloride, Molecular Structure \\ The molecular structure of $\mathrm{C}_{7} \mathrm{H}_{7} \mathrm{SO}_{2} \mathrm{Cl}$ was determined by X-ray diffraction and refined to $R=$ \\ 0.060 and $R_{\mathrm{w}}=0.053$ from 1170 unique reflections. The unit cell is triclinic, $\mathrm{P} \overline{1}$, with $Z=2, a=$ \\ 8.528(5), $b=8.214(3), c=6.306(2) \AA ; \alpha=95.47(3), \beta=104.41(3), \gamma=93.08(4)^{\circ} ; \mathrm{V}=$ \\ $424.6(3) \AA^{3} ; \mu=6.30 \mathrm{~cm}^{-1} ; \delta_{\text {calc }}=1.49 \mathrm{Mg} \cdot \mathrm{m}^{-3} ; \mathrm{F}(000)=196$. \\ The dihedral angle between the benzene ring and the $\mathrm{Cl}-\mathrm{S}-\mathrm{C}(1)$ plane $\left[84.3(1)^{\circ}\right]$ is similar to \\ those observed for benzenesulfonyl chlorides where molecular packing results from normal van \\ der Waals interactions [1,2]. The compound has normal bond lengths and angles. Distortion of \\ the benzene ring is in agreement with the predicted $\sigma$ - and $\pi$-effects of substituent groups [3]. No \\ significantly short intermolecular distances were found.
}

\section{Introduction}

The study of cyclic compounds has received considerable attention in recent years. In particular, a great amount of information is available about the geometrical distortions of the benzene ring caused by substitution. These deformations are generally more pronounced in the part of the ring nearest to the substituent ( $a$ bonds, $\alpha$ and $\beta$ angles in Fig. 1) [4]. Unlike bond length variations, which are rather difficult to measure accurately, changes in the ring angles can be measured very well. In the case of two substituents, the effects on the internal angles would act independently and could be superimposed [5].

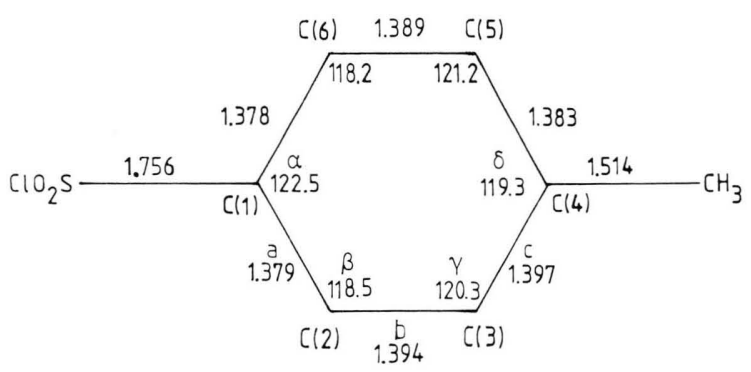

Fig. 1. Labelling of the $\mathrm{C}-\mathrm{C}$ bonds and $\mathrm{C}-\mathrm{C}-\mathrm{C}$ angles in the benzene ring and some of the molecular parameters as obtained in this work. Distances are in $\AA$ and angles in degrees.

\footnotetext{
* Reprint requests to Dr. R. R. Filgueira.

Verlag der Zeitschrift für Naturforschung, D-7400 Tübingen $0340-5087 / 86 / 0900-1107 / \$ 01.00 / 0$
}

In order to extend the knowledge concerning this type of ring systems, the study of $\mathrm{C}_{7} \mathrm{H}_{7} \mathrm{SO}_{2} \mathrm{Cl}$ was undertaken. The two main questions posed by this molecule were: (i) to find the orientation of the $\mathrm{SO}_{2} \mathrm{Cl}$ group with respect to the benzene ring, and (ii) to obtain a first estimation of the distorsive effect introduced in the ring by the $\mathrm{SO}_{2} \mathrm{Cl}$ group.

\section{Experimental}

A crystal of irregular shape of approximate dimensions $0.3 \times 0.2 \times 0.1 \mathrm{~mm}$ was coated with Nujol and mounted in a sealed Lindemann capillary. Data were collected on a Huber four-circle diffractometer using graphite-monochromatized $\operatorname{MoK}_{\alpha}(\lambda=0.7093 \AA)$ radiation. Lattice parameters were obtained from $2 \vartheta$ values (ranging from 7 to $36^{\circ}$ ) of 14 reflections. Data were measured by using the scan mode; scan width for each reflection was $1^{\circ}$ with variable scan time $(13-78 \mathrm{~s})$. The range explored was 2 to $50^{\circ}$ in $2 \vartheta$. Three standard reflections ( $\overline{1} 01, \overline{2} 02$ and $0 \overline{4} 4$ ), monitored every $120 \mathrm{~min}$, showed an overall $\sigma$ (relative instability) of 0.02 .

1501 unique reflections from a total of 1946 gave a $R_{\text {int }}=2.4 \%$. Data were corrected for Lorentz and polarization effects but not for absorption; isotropic extinction coefficient was $2.24 \times 10^{-7}$.

The structure was solved by direct methods [6] and refined by full-matrix least-squares method on F's, with about 12 data per independent parameter and using anisotropic thermal parameters for non-hydrogen atoms. All hydrogen atoms were located from subsequent electron density synthesis, but not refined. Stereochemical calculated positions for hydrogen atoms were almost coincident with experimental 
values. The final agreement factors, calculated from 1170 unique reflections with $\mathrm{I}>3 \sigma(\mathrm{I})$, were: $R=$ $6.0 \%, R_{\mathrm{w}}=5.3 \%$. Modified unit weights were used, $\mathrm{W}=(\mathrm{THRES} / \mathrm{F})^{2}$ for $\mathrm{F} \geqslant$ THRES; $\mathrm{W}=1.0$ for $\mathrm{F}<$ THRES; threshold $=29$, and Dunitz-Seiler modified weighting scheme [7]: $\mathrm{W}^{\prime}=\mathrm{W} \cdot \exp [$ SHARP $\left.(\sin \vartheta / \lambda)^{2}\right]$; sharpening value $=20.0$.

E.s.d. of an observation of unit weight was 1.69 ; the largest parameter shift was 0.02 ; the final difference map showed no peaks of structural significance.

Final atomic coordinates and equivalent thermal parameters are given in Table I*.

Table I. Positional parameters and their estimated standard deviations.

\begin{tabular}{lllll}
\hline Atom & $x$ & $y$ & $z$ & $\mathrm{~B}\left(\AA^{2}\right)$ \\
\hline $\mathrm{S}$ & $0.7256(1)$ & $0.24097(9)$ & $0.3660(1)$ & $4.59(1)$ \\
$\mathrm{Cl}$ & $0.9546(1)$ & $0.2502(1)$ & $0.5716(2)$ & $6.18(2)$ \\
$\mathrm{O}(1)$ & $0.6185(4)$ & $0.2235(4)$ & $0.5052(5)$ & $6.22(6)$ \\
$\mathrm{O}(2)$ & $0.7248(6)$ & $0.3794(3)$ & $0.2469(6)$ & $6.77(7)$ \\
$\mathrm{C}(1)$ & $0.7195(4)$ & $0.0584(3)$ & $0.1940(5)$ & $4.22(4)$ \\
$\mathrm{C}(2)$ & $0.6533(4)$ & $-0.0845(4)$ & $0.2466(5)$ & $4.57(5)$ \\
$\mathrm{C}(3)$ & $0.6543(4)$ & $-0.2305(4)$ & $0.1148(6)$ & $4.97(6)$ \\
$\mathrm{C}(4)$ & $0.7230(4)$ & $-0.2310(4)$ & $-0.0644(6)$ & $4.98(6)$ \\
$\mathrm{C}(5)$ & $0.7860(5)$ & $-0.0846(5)$ & $-0.1132(6)$ & $5.36(6)$ \\
$\mathrm{C}(6)$ & $0.7846(4)$ & $0.0621(4)$ & $0.0151(5)$ & $5.01(6)$ \\
$\mathrm{C}(7)$ & $0.7292(7)$ & $-0.3907(5)$ & $-0.2023(8)$ & $6.89(9)$ \\
\end{tabular}

Starred atoms were not refined. Anisotropically refined atoms are given in the form of the isotropic equivalent thermal parameter defined as: $(4 / 3) \cdot\left[a^{2} \cdot \mathrm{B}(1,1)+b^{2} \cdot \mathrm{B}(2,2)+\right.$ $c^{2} \cdot \mathrm{B}(3,3)+a b(\cos \gamma) \cdot \mathrm{B}(1,2)+a c(\cos \beta) \cdot \mathrm{B}(1,3)+b c(\cos$ $\alpha) \cdot \mathrm{B}(2,3)]$.

\section{Description of the Structure}

Figure 2 shows the labelling of the atoms in an ORTEP diagram of the molecule. Bond lengths and angles with estimated standard deviations are shown in Tables II and III, respectively. The aromatic ring is planar within the limits of accuracy of the atomic parameters.

The distance between nearest stacked aromatic ring planes related by inversion through $(1 / 2,0,0)$ is $3.654(3) \AA$, the shift between centers being

\footnotetext{
* Lists of structure factors, anisotropic thermal parameters and Table of root-mean square amplitudes of thermal vibrations have been deposited at Fachinformationszentrum Energie, Physik, Mathematik GmbH, D-7514 Eggenstein-Leopoldshafen 2. The registry-Nr., CSD 51996, the name of the author, and the reference should be given.
}

Table II. Bond distances $[\AA]$.

\begin{tabular}{lll}
\hline Atom 1 & Atom 2 & Distance \\
\hline $\mathrm{S}$ & $\mathrm{Cl}$ & $2.051(1)$ \\
$\mathrm{S}$ & $\mathrm{O}(1)$ & $1.426(3)$ \\
$\mathrm{S}$ & $\mathrm{O}(2)$ & $1.421(3)$ \\
$\mathrm{S}$ & $\mathrm{C}(1)$ & $1.756(2)$ \\
$\mathrm{C}(1)$ & $\mathrm{C}(2)$ & $1.379(4)$ \\
$\mathrm{C}(1)$ & $\mathrm{C}(6)$ & $1.378(4)$ \\
$\mathrm{C}(2)$ & $\mathrm{C}(3)$ & $1.394(4)$ \\
$\mathrm{C}(3)$ & $\mathrm{C}(4)$ & $1.397(5)$ \\
$\mathrm{C}(4)$ & $\mathrm{C}(5)$ & $1.383(5)$ \\
$\mathrm{C}(4)$ & $\mathrm{C}(7)$ & $1.514(4)$ \\
$\mathrm{C}(5)$ & $\mathrm{C}(6)$ & $1.389(4)$ \\
\hline
\end{tabular}

Numbers in parentheses are estimated standard deviations in the least significant digits.

Table III. Bond angles $\left[{ }^{\circ}\right]$.

\begin{tabular}{llll}
\hline Atom 1 & Atom 2 & Atom 3 & Angle \\
\hline $\mathrm{Cl}$ & $\mathrm{S}$ & $\mathrm{O}(1)$ & $105.0(1)$ \\
$\mathrm{Cl}$ & $\mathrm{S}$ & $\mathrm{O}(2)$ & $105.7(2)$ \\
$\mathrm{Cl}$ & $\mathrm{S}$ & $\mathrm{C}(1)$ & $101.63(8)$ \\
$\mathrm{O}(1)$ & $\mathrm{S}$ & $\mathrm{O}(2)$ & $120.7(2)$ \\
$\mathrm{O}(1)$ & $\mathrm{S}$ & $\mathrm{C}(1)$ & $110.8(1)$ \\
$\mathrm{O}(2)$ & $\mathrm{S}$ & $\mathrm{C}(1)$ & $110.9(2)$ \\
$\mathrm{S}$ & $\mathrm{C}(1)$ & $\mathrm{C}(2)$ & $118.6(2)$ \\
$\mathrm{C}(2)$ & $\mathrm{C}(1)$ & $\mathrm{C}(6)$ & $122.5(3)$ \\
$\mathrm{C}(1)$ & $\mathrm{C}(2)$ & $\mathrm{C}(3)$ & $118.5(3)$ \\
$\mathrm{C}(2)$ & $\mathrm{C}(3)$ & $\mathrm{C}(4)$ & $120.3(3)$ \\
$\mathrm{C}(3)$ & $\mathrm{C}(4)$ & $\mathrm{C}(5)$ & $119.3(3)$ \\
$\mathrm{C}(3)$ & $\mathrm{C}(4)$ & $\mathrm{C}(7)$ & $120.1(3)$ \\
$\mathrm{C}(5)$ & $\mathrm{C}(4)$ & $\mathrm{C}(7)$ & $120.6(3)$ \\
$\mathrm{C}(4)$ & $\mathrm{C}(5)$ & $\mathrm{C}(6)$ & $121.2(3)$ \\
$\mathrm{C}(1)$ & $\mathrm{C}(6)$ & $\mathrm{C}(5)$ & $118.2(3)$ \\
$\mathrm{S}$ & $\mathrm{C}(1)$ & $\mathrm{C}(6)$ & $118.9(2)$ \\
\hline
\end{tabular}

Numbers in parentheses are estimated standard deviations in the least significant digits.

3.17(2) $\AA$. Benzene planes make an angle of $26.7(1)^{\circ}$ with $\left(\begin{array}{lll}1 & 0 & 0\end{array}\right)$. Packing is shown in Fig. 3; it may be described as layers perpendicular to $\left[\begin{array}{lll}1 & 0 & 0\end{array}\right]$, composed of equally oriented molecules, intercalated with layers formed by centrosymmetric molecules. Interlayer planes are occupied alternatively by chlorine and oxygen atoms as a consequence of the perpendicularity between the ring and the $\mathrm{Cl}-\mathrm{S}-\mathrm{C}(1)$ planes $\left[84.3(1)^{\circ}\right]$. The orientation of the sulfonyl chloride group is such that the planes $\mathrm{O}(1)-\mathrm{S}-\mathrm{C}(1)$ and $\mathrm{O}(2)-\mathrm{S}-\mathrm{C}(1)$ define angles of $15.6(1)$ and $27.7(1)^{\circ}$, respectively, with the aromatic ring plane. The angular disposition of $\mathrm{Cl}, \mathrm{O}(1), \mathrm{O}(2)$ and $\mathrm{C}(1)$ about $\mathrm{S}$ 


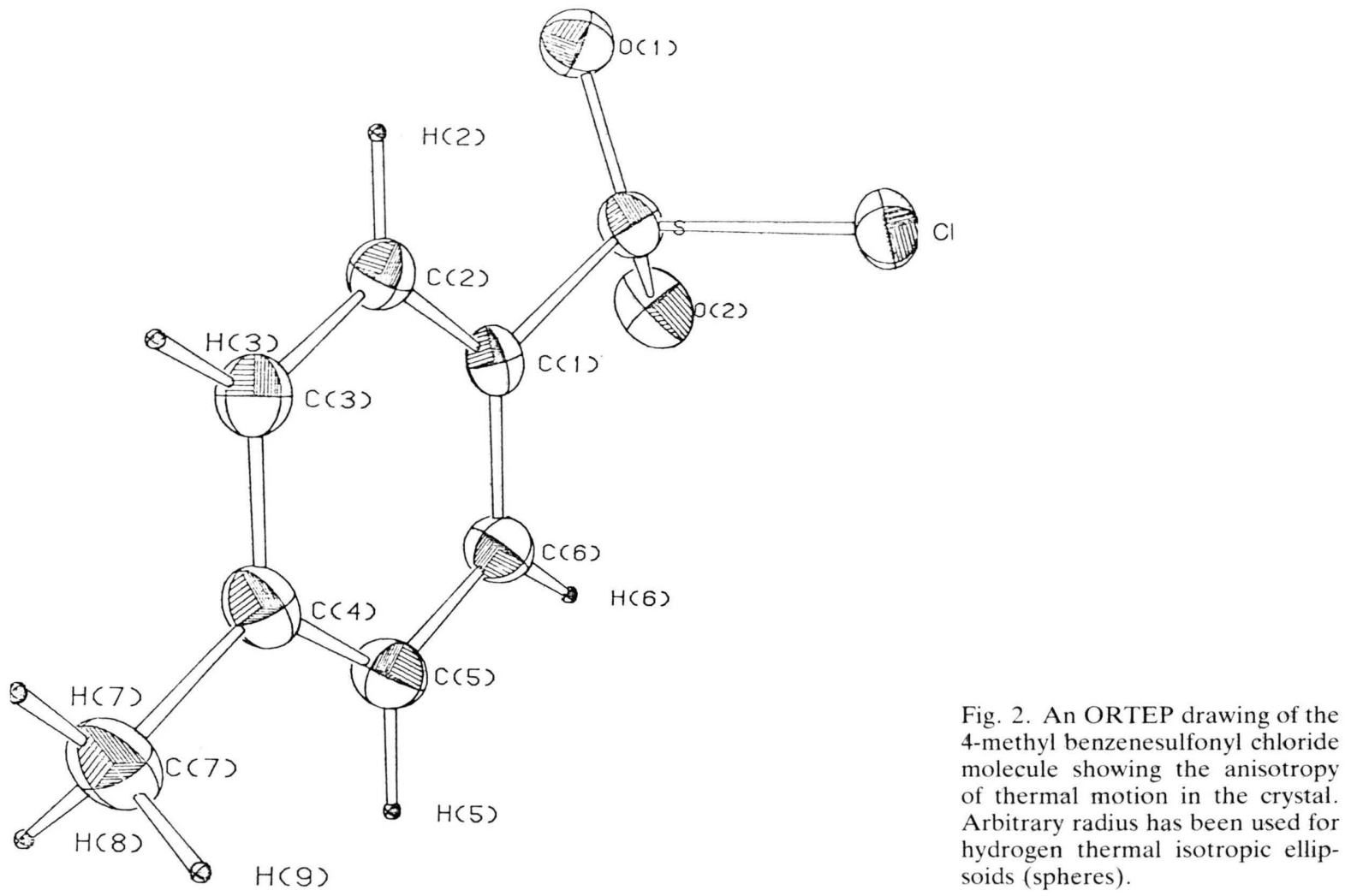

departs significatively from a regular tetrahedral arrangement, the smallest and the highest bond angles being $101.63(8)^{\circ} \quad[\mathrm{Cl}-\mathrm{S}-\mathrm{C}(1)]$ and $120.7(2)^{\circ}$ $[\mathrm{O}(1)-\mathrm{S}-\mathrm{O}(2)]$, respectively. These minimum and maximum values are almost coincident with those found in 2,4,5-trichlorobenzenesulfonyl chloride [2] and similar to those observed in other benzenesulfonyl chlorides $[1,8,9]$. The $\mathrm{S}-\mathrm{Cl}$ distance is that of a single bond and $\mathrm{S}-\mathrm{O}$ and $\mathrm{S}-\mathrm{C}$ distances display similar values to those found in sulfones $[1,8,9]$.

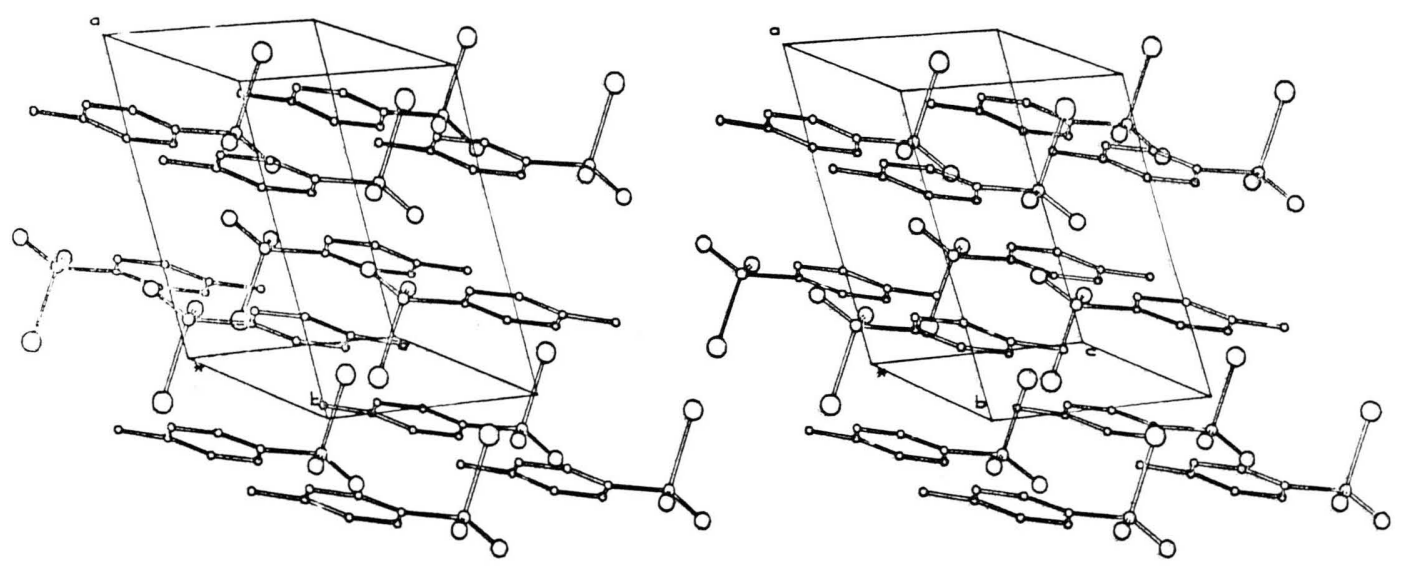

Fig. 3. Stereoscopic view of the structure showing the arrangement of benzene ring in layers perpendicular to [ 100$]$. Hydrogen atoms have been omitted for sake of clarity. 


\section{Discussion}

The orientation of the $\mathrm{SO}_{2} \mathrm{Cl}$ group is such that the $\mathrm{C}(1)-\mathrm{S}-\mathrm{Cl}$ plane defines an angle of $84.3(1)^{\circ}$ with the benzene plane. This value was also found for other crystalline benzenesulfonyl chlorides $[1,2]$ where packing forces are mainly due to normal van der Waals interactions. A value of $75.3^{\circ}$ has been obtained for this angle in benzenesulfonyl chloride $\left(\mathrm{C}_{6} \mathrm{H}_{5} \mathrm{SO}_{2} \mathrm{Cl}\right)$ by refinement of gas electron diffraction data [8]. The asymmetry has been attributed to a possible interaction between hydrogen and oxygen atoms within the same molecule although asymmetry has been also found in $\mathrm{C}_{6} \mathrm{H}_{5} \mathrm{CH}_{2} \mathrm{Cl}$ and $\mathrm{C}_{6} \mathrm{H}_{5} \mathrm{CH}_{2} \mathrm{Br}$ [10], where electrostatic interactions are absent [8]. Care must be taken, however, when comparing data from gaseous and crystalline phases. Packing forces seem to play a dominant role in determining the angle between $\mathrm{C}(1)-\mathrm{S}-\mathrm{Cl}$ and aromatic ring planes.

Asymmetry in the ring can be appreciated from Fig. 1 ; it may be probably attributed to an interaction between $\mathrm{H}(3)$ and $\mathrm{O}(2)$ from $\left(\begin{array}{lll}0 & 1 & 0\end{array}\right)$ translation related molecule (distance $\mathrm{H}(3)-\mathrm{O}(2)=2.678(2) \AA$ ). The other meta hydrogen (with respect to the $\mathrm{SO}_{2} \mathrm{Cl}$ group), $\mathrm{H}(5)$, does not interact appreciably with neighbouring electronegative atoms (distance $\mathrm{H}(5)-\mathrm{O}(1)=3.488(3) \AA)$. The interaction at $\mathrm{H}(3)$ presumably produces the polarization of the $\mathrm{C}(3)-\mathrm{H}(3)$ bond. The expected effect at $\mathrm{C}(3)$ is a decrease in the $\mathrm{C}(2)-\mathrm{C}(3)-\mathrm{C}(4)$ angle and an increase in $\mathrm{C}(2)-\mathrm{C}(3)$ and $\mathrm{C}(3)-\mathrm{C}(4)$ distances, as observed. Note that this effect nearly compensates the distortions of the ring due to polarization of the $\pi$-electron system of the ring (with little net electron transfer) [11] produced by the methyl group (see discussion below).

Ring deformation parameters corresponding to a number of substituents have been derived from structural data of polysubstituted benzene rings using linear regression techniques $[5,12]$, but no data are available for the $\mathrm{SO}_{2} \mathrm{Cl}$ group.

Although distortions of the benzene ring as a consequence of the chlorosulfonyl group could not be accurately determined (X-ray crystallographic data were not corrected neither by thermal motion nor by non-spherical distribution of the valence electrons), they were semi-quantitatively estimated. Assuming that the substituent effects on the internal angles and bond distances of the ring in para-substituted benzene derivatives are additive ([3] and references therein), the contribution to internal angle and bond distance distortions due to the $\mathrm{SO}_{2} \mathrm{Cl}$ group were calculated by substraction of the $p$-methyl group effects. Values of deformation parameters for $\mathrm{SO}_{2} \mathrm{Cl}$, obtained in this way, are collected in Table IV. Distortions of the ring produced by $\mathrm{CH}_{3}$ are due to the polarization of the $\pi$-electron system of the ring with little net electron transfer [11]. Angular and bond length deformation parameters for $\mathrm{CH}_{3}$ group were taken from ref. [12]. Structural data for other crystalline benzenesulfonyl chlorides have not been considered here due to poor quality of data $[1,2]$; that is, estimated standard deviations are higher than $0.3^{\circ}$ in the bond angles and $0.005 \AA$ in the bond distances.

As mentioned above, the difference between $C(4)-C(5)-C(6)$ and $C(2)-C(3)-C(4)$ angles are larger than experimental errors; we have chosen the value $C(4)-C(5)-C(6)=121.3^{\circ}$ to calculate the distortions induced by the $\mathrm{SO}_{2} \mathrm{Cl}$ group. This assumption gives a positive $\Delta \gamma$ deformation parameter for the chlorosulfonyl group, which is in agreement with the observed increase in $\alpha$, and is also associated with a decrease of $\beta$ and a shortening of the $a$ bonds $[3,5,13]$. In spite of the above-mentioned sources of error, these estimated values are in agreement with the $\sigma$-electron-withdrawing character of the $\mathrm{SO}_{2} \mathrm{Cl}$ group, and can be mainly appreciated in the shortening of the $a$ bonds (see Fig. 1) [1.379(4) $\AA$ and

Table IV. Values of deformation parameters for $\mathrm{SO}_{2} \mathrm{Cl}$ and $\mathrm{CH}_{3}$ substituents. Angle variations are in degrees and bond distance variations are in $\AA \times 10^{3}$.

\begin{tabular}{lcclcccc}
\hline Substituent & $\Delta \alpha^{\mathrm{a}}$ & $\Delta \beta$ & $\Delta \gamma$ & $\Delta \delta$ & $\Delta a$ & $\Delta b$ & $\Delta c$ \\
\hline $\mathrm{CH}_{3}{ }^{\mathrm{b}}$ & $-0.51(11)$ & $0.20(6)$ & $0.95(6)$ & $-1.78(11)$ & $-3(1)$ & $-2(1)$ & $4(1)$ \\
$\mathrm{SO}_{2} \mathrm{Cl}^{\mathrm{c}}$ & 3.1 & -1.7 & 0.25 & 1.1 & -8 & $\mathrm{~d}$ & $\mathrm{~d}$
\end{tabular}

a $\Delta \alpha, \Delta \beta, \Delta \gamma, \Delta \delta$, and $\Delta a, \Delta b, \Delta c$ refer to $\mathrm{SO}_{2} \mathrm{Cl}$ group (ipso substituent); ${ }^{\mathrm{b}}$ angular and bond distance deformation parameters for $\mathrm{CH}_{3}$ group were taken from Table IV of ref. [12]; " values for $\mathrm{SO}_{2} \mathrm{Cl}$ group were calculated from experimental X-ray data, this work; ${ }^{\mathrm{d}} \Delta b$ and $\Delta c$ were not calculated because they are much less sensitive than $\Delta a$ to the presence of the ipso substituent and experimental errors may be larger than distortions produced by $\mathrm{SO}_{2} \mathrm{Cl}$ group. 
$1.378(4) \AA]$ and in the increase of the $\alpha$ angle $\left[122.5(3)^{\circ}\right]$. Bond distance variations are more affected by experimental errors than bond angle variations, so that angular deformations in the ring provide more reliable data to relate them to the electronic properties of the substituents.
Financial support from the Consejo Nacional de Investigaciones Científicas y Técnicas, the Comisión de Investigaciones Científicas de la Provincia de Buenos Aires and the American States Organization is greatly appreciated.
[1] B. N. Gogoi and A. Hargreaves, Acta Crystallogr. B 26, 2132 (1970).

[2] P. M. Alzari, G. Rigotti, A. Navaza, and A. Brunetti, to be published.

[3] A. Domenicano, 11th Course of the International School of Crystallography, Italy, 1985. Lecture Notes, p. 315.

[4] M. Colapietro, A. Domenicano, C. Marciante, and G. Portalone, Z. Naturforsch. 39b, 1361 (1984).

[5] A. Domenicano and P. Murray-Rust, Tetrahedron Lett. 24, 2283 (1979).

[6] P. Main, S. J. Fiske, S. E. Hull, L. Lessinger, G. Germain, J.-P. Declercq, and M. M. Woolfson. MULTAN 82. A system of computer programs for the automatic solution of crystal structures from X-ray diffraction data. Univ. of York, York, England (1982).
[7] J. D. Dunitz and P. Seiler, Acta Crystallogr. B 29, 589 (1973).

[8] J. Brunvoll and I. Hargittai, J. Mol. Struct. 30, 361 (1976).

[9] M. Hargittai and I. Hargittai, J. Mol. Struct. 20, 283 (1974).

[10] N. I. Sadova, L. V. Vilkov, I. Hargittai, and J. Brunvoll, J. Mol. Struct. 31, 131 (1976).

[11] A. Domenicano and A. Vaciago, Acta Crystallogr. B 35, 1382 (1979).

[12] R. Norrestam and L. Schepper, Acta Chem. Scand. A 35, 91 (1981).

[13] A. Domenicano, P. Murray-Rust, and A. Vaciago, Acta Crystallogr. B 39, 457 (1983). 